\title{
Insecticidal activity of entomopathogenic fungi and neem-based biopesticide (Azadirachta indica) on Spodoptera litura
}

\author{
Ade Aliyya ${ }^{1}$, Apriwi Zulfitri ${ }^{1}$, Umi Zakiah ${ }^{2}$, Arief Heru Prianto ${ }^{1}$, Titik Kartika ${ }^{1}$, Nova \\ Hariani $^{2}$, Deni Zulfiana ${ }^{1}$, and Ikhsan Guswenrivo ${ }^{1 *}$ \\ ${ }^{1}$ Research Center for Biomaterials, Indonesian Institute of Sciences, Indonesia \\ ${ }^{2}$ Faculty of Mathematics and Natural Sciences, Mulawarman University, Indonesia
}

\begin{abstract}
Chemical pesticide has been used extensively to control Spodoptera litura that attack economically important crops.The use of synthetic pesticides with high intensity is detrimental to the quality of life. The objective of this study was to evaluate the insecticidal activity of entomopathogenic fungi and neem-based biopesticide on S. litura using spraying and forced feeding method. The treatments were spore solution of Trichoderma viride, Metarhizium sp. T4.B23, Metarhizium sp. B2.2 applied at $10^{8} \mathrm{spores} / \mathrm{mL}$, biopesticide formulation containing neem extract (Agr1) at $10 \%(\mathrm{v} / \mathrm{v})$, and water as control. Each treatment was sprayed $0.3 \mathrm{~mL}$ directly onto larvae of $S$. litura while in forced feeding method, the larvae were fed on $1 \mathrm{gr}$ of treated water spinach. Entomopathogenic fungal spore solution did not show efficacy on $S$ litura larvae in both methods, while Agr 1 caused 90 and $40 \%$ mortality in spraying and forced feeding method, respectively. Furthermore, the efficacy of Agr 1 was compared to Agr 2 that contains neem extract and wood vinegar. Agr 2 caused $100 \%$ mortality when sprayed onto $S$. litura larvae, and more than $90 \%$ of larvae were died when forced to feed treated water spinach. Agr2 has better potential than Agr1 to control S.litura.
\end{abstract}

\section{Introduction}

Spodoptera litura Fabricius (Lepidoptera: Noctuidae) in the larva phase is polyphagous, a pest to 15 species of the vegetable plant [1] both in the vegetative and generative stages, thus causing damage to leaves and fruits. Moreover, an outbreak of $S$. litura will cause host plant and yield losses [2]. S. litura is also one of the important pests to chili (Capsicum annum L.) and has become one of the limit factors of chili cultivation [3].

The less eco-friendly chemical synthetic pesticide has been used to control S. litura in agriculture. The loss of untargeted insect such as insect pests' natural enemies and insect pest resistance to one or more pesticides are increasingly urgent worldwide problems due to the overtime application of synthetic pesticides. The natural enemy has a vital role in controlling pests as a biological agent. One of the promising options of biological agents for controlling

* Corresponding author: apriwi07@yahoo.com 
S. litura is entomopathogenic fungi, such as Metarhizium sp., because of their high reproduction capacity, short life cycle, spore-forming ability under the bad condition to sporulation and growth, target-selective, and low probability to cause resistance [4]. Entomopathogenic fungi can infect insects and arthropods directly, and most of these fungi are not dangerous to plants and are relatively not poisonous to other animals [5].

Another potential insect pest control agent to be used as a biopesticide is Azadirachta indica seed extract. Neem-based products including traditional preparations and formulations, have been used extensively to control of insect pests attacking crops [6]. Formulation of $A$. indica seeds has been reported showing antifeedant [7,8], fecundity suppression [9], growth inhibition [10], ovicidal and larvicidal activity [11] and repellence [8] against many different insects at low dosages. $A$. indica molecules weaken the cuticle defense system of young instars causing easy penetration of pathogenic organisms [12]. $A$. indica containing limonoids as active pesticide ingredients. The major limonoid compound found are azadirachtin salanin, meliantriol, and nimbin with azadirachtin accounted for the most active and abundant phytochemical content of $A$. indica [13]. Azadirachtin isomer $\mathrm{A}$ is the most plentiful and biologically active in azadirachtin, which has shown repellent, antifeedant, and insecticidal activity against pests [13]. This study aimed to evaluate the insecticidal activity of fungal spore suspension and $A$. indica seed extract against $S$. litura.

\section{Materials and methods}

The research was carried out from December 2020 to March 2021 in the green house of Zoologi divison, Research Center for Biology and Laboratory of Bioproduct Formulation of iLaB, Research Center for Biomaterials, LIPI.

\subsection{Fungal culture}

Isolate of Trichoderma viride, Metarhizium sp. T4.B23, and Metarhizium sp. B2.2 was sub cultured on potato dextrose agar (PDA) and then incubated in a room at $27 \pm 1^{\circ} \mathrm{C}$ for 21 days. Then, 21 days, the sub cultured isolate was inoculated to autoclaved parboiled rice media and incubated for 14 - 21 days until spores emerged. The spores were then harvested using a sieve, and the density was calculated per 1 gram of pure spores.

\subsection{Bioassay of entomopathogenical fungi and biopesticide formulation containing neem extract (Agr1) against S. litura using spraying and forced feeding method}

Agr1 is a biopesticide formulation containing $A$. indica seed extract at $40 \mathrm{EC}$. The bioassay was conducted to evaluate the toxicity of both agents against the $2^{\text {nd }}-3^{\text {rd }}$ instar of $S$. litura in a controlled environment. Agr1 formulation concentration used in this bioassay was 5\% $(\mathrm{v} / \mathrm{v})$ in $\mathrm{dH}_{2} \mathrm{O}$, while the spore density of the fungal applied was $10^{8}$ spores $/ \mathrm{mL}$.

For the spraying method, as much as $0.3 \mathrm{~mL}$ of each treatment was directly sprayed to S. litura body, while in the forced feeding method, 5 grams of water spinach leaf were sprayed with $1 \mathrm{~mL}$ of each treatment, respectively. After sprayed, the larvae were put in a disposable petri dish and given water spinach as food regularly. $\mathrm{dH}_{2} \mathrm{O}$ was used as a control, and each treatment used 33 larvae.

In the forced feeding method, every 5 grams of water spinach leaves was sprayed using $1 \mathrm{~mL}$ treatment solution, and each $S$. litura was fed with 1 gram sprayed leaves without prior starvation. Control leaf was sprayed using $\mathrm{dH}_{2} 0$. The larvae were fed with untreated water spinach after all treated leaves were consumed by the larvae. The mortality observation for 
both methods was conducted at 2 hours, 4 hours, and 6 six hours after treatment and every 24 hours for seven days. The treatments were incubated at $26-28{ }^{\circ} \mathrm{C}$.

\subsection{Bioassay of Agr1 and Agr2 against S. litura using spraying and forced feeding method}

Agr2 is an improvement of Agr1 with the addition of pyroligneous acid as known as wood vinegar. The concentration used in this assay was $10 \%(\mathrm{v} / \mathrm{v})$ for both formulations. The method, observation, replication, and incubation condition were conducted in the same manner as the previous bioassay.

\section{Result}

S. litura was sprayed using treatment solution. After spraying, S. litura was observed during 168 hours to observe the insecticidal effect of treatment solution, especially the effect of spores that came into the $S$. litura body through their trachea and other pores. Observations were made to provide sufficient time for spores of T. viride, Metarhizium sp. T4.B23, and Metarhizium sp. B2.2 attaches to insect cuticle, germinates, penetrates body cavity, and grows into mycelium. After the mycelium growth, thin-walled blastospores were formed, circulated within the insect body, and eventually forming lethal mycelial biomass. This mycelium grows back through the cuticle, covers the body surface, and develops a large number of distributive conidia.

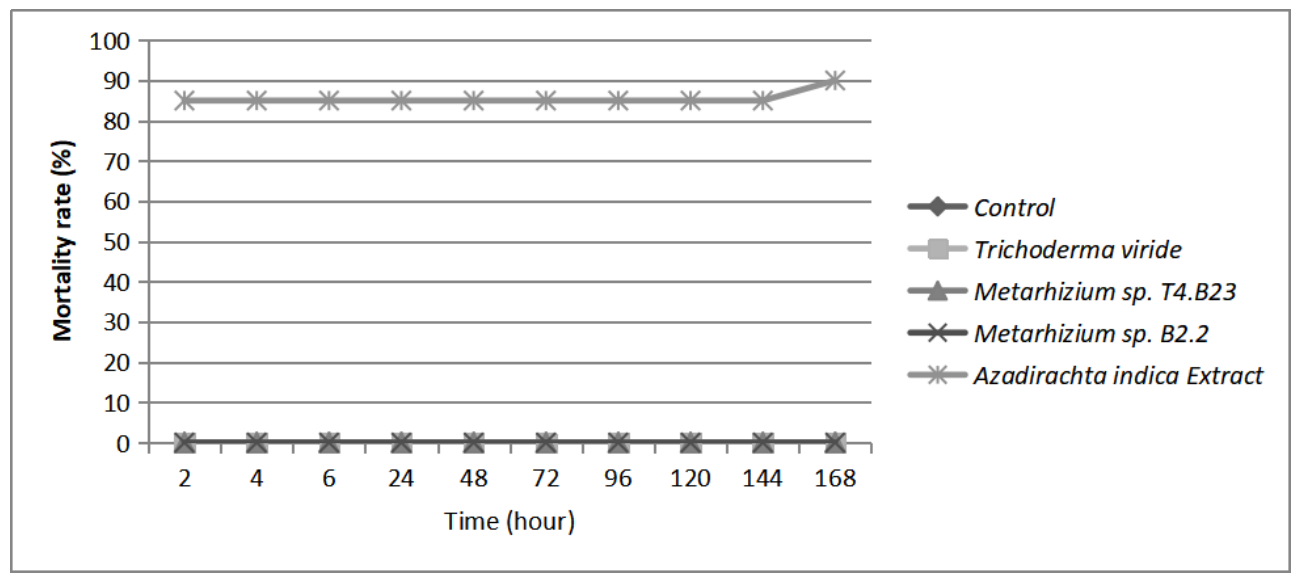

Fig.1 Mortality percentages of $S$. litura after sprayed using $\mathrm{dH}_{2} \mathrm{O}$, spore suspension of $T$. viride, Metarhizium sp. T4.B23, Metarhizium sp. B2.2, and A. indica seed extract

A. indica seed extract had the highest mortality rate (Fig. 1). Spore suspension of T. viride, Metarhizium sp. T4.B23, and Metarhizium sp. B2.2 did not cause death in S. litura, possibly caused by fungal spores that were unable to infect and colonize $S$. litura. S. litura was also treated with once sprayed leaves. In forced feeding method, leaves sprayed with $\mathrm{dH} 2 \mathrm{O}$, spore's suspension of $T$. viride, Metarhizium sp. T4.B23, Metarhizium sp. B2.2, and A. indica seed extract are used as feed to S. litura, respectively. Untreated leaves were given to the larvae after all treated leaves were cousumed was done to observe the treatment solution's effect, to the digestion system of $S$. litura after consumed. 


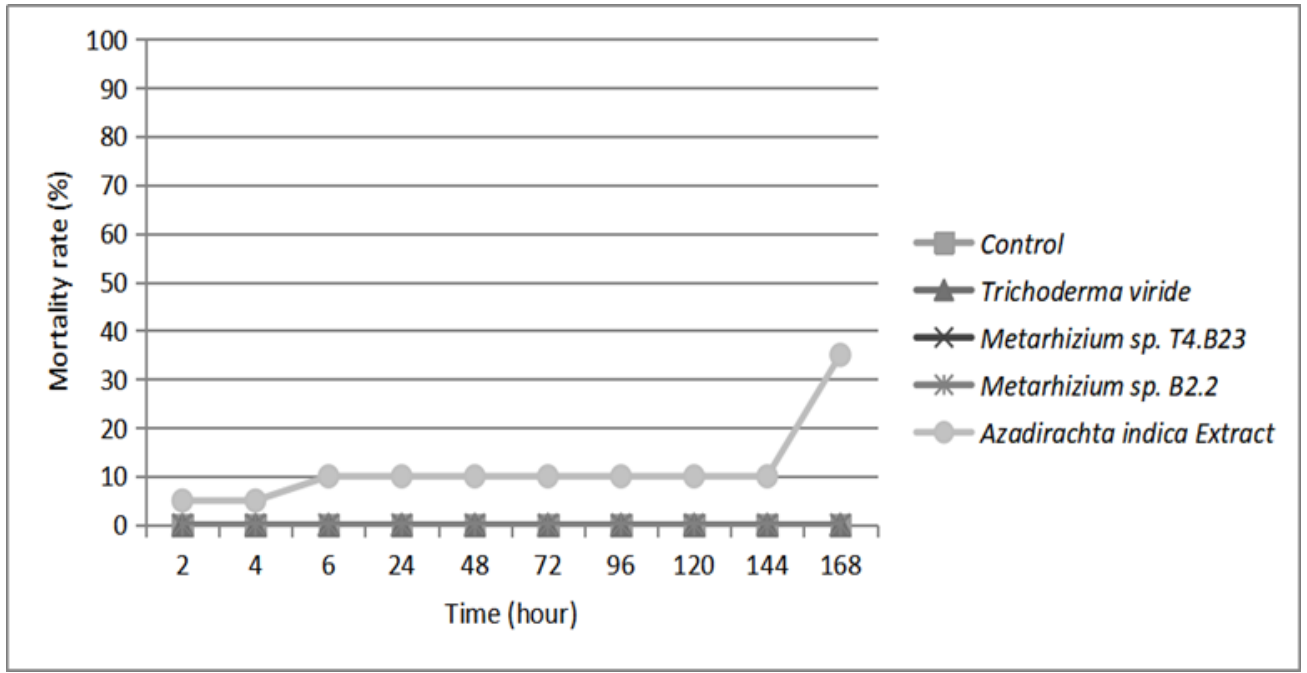

Fig. 2 Mortality percentages of $S$. litura after fed with leaves sprayed using $\mathrm{dH}_{2} \mathrm{O}$, spore suspension of T. viride, Metarhizium sp. T4.B23, Metarhizium sp. B2.2, and A. indica seed extract

Death only occurred after $S$. litura was force-fed with leaves sprayed with $A$. indica extract (Fig. 2). Forced feeding of $S$. litura by spraying the leaves using $A$. indica extract did not directly cause death. The death of $S$. litura occurred after several days after treatment. $S$. litura that was fed with leaves sprayed using spore suspension did not show any insecticidal activity during observation time. During the observation, the behavior of $S$. litura also did not change. It indicated that the spore of T. viride, Metarhizium sp. T4.B23, and Metarhizium sp. B2.2 cannot infect $S$. litura through the digestion system.

The insecticidal activity of Agr1 was then compared to Agr 2. Agr 2 is an improvement of Agr1 with the addition of wood vinegar. Both formulations were sprayed directly to the larvae three times at 0 hour, 24 hours, and 48 hours. Repeated spraying was conducted to observe the effect of accumulated $A$. indica extract on the $S$. litura body surface.

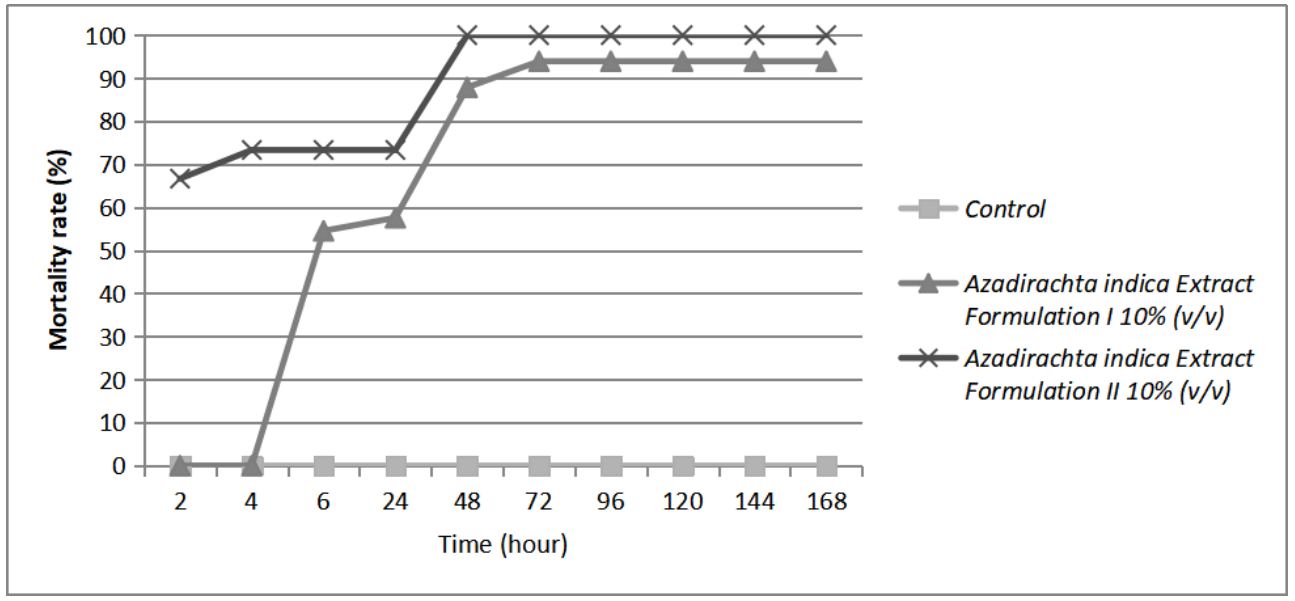

Fig. 3. Mortality percentages of $S$. litura after sprayed using $\mathrm{dH}_{2} \mathrm{O}$, Agr1 (Formulation I) and Agr2 (Formulation II) 
Agr1 and Agr2 caused mortality to $S$. litura and repeated spraying on the $S$. litura body surface may be increasing the mortality rate. Wood vinegar in formulation II increased the mortality rate and shortened the time for S. litura to die.

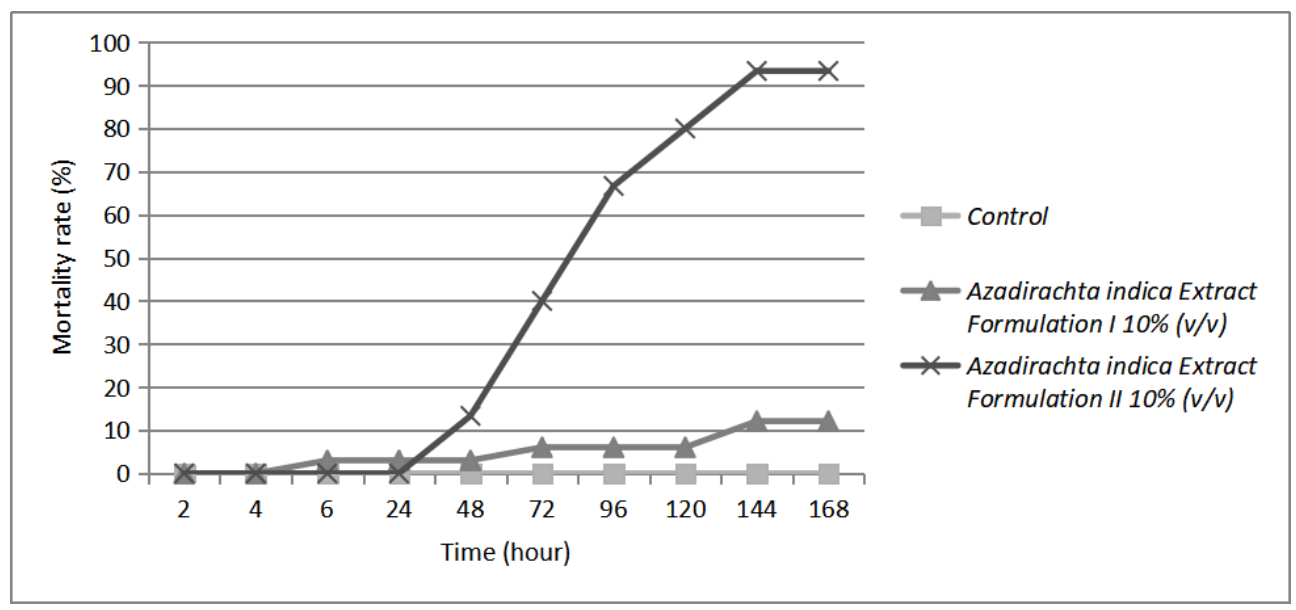

Fig. 4 Mortality percentages of $S$. litura after fed with leaves that sprayed using $\mathrm{dH}_{2} \mathrm{O}$, Formulation I of $A$. indica extract, and Formulation II of $A$. indica seed extract

Meanwhile in force feeding method, the mortality rate caused by Agr2 was higher than that of Agr 1. Mortality rate for the two formulations was increased during the observation. However, the mortality rate of Agr1 was not as significant as Agr2. The mortality rate of Agr1 only $12 \%$ at the end of observation and doesn't increase much during the observation. The mortality rate of larvae fed with Agr2 treated leaves was kept increasing during observation and reached $93 \%$ after 144 hours of observation.

\section{Discussion}

The decreased infection and penetrating ability of Metarhizium sp. T4.B23 and Metarhizium sp. B2.2 is may be caused by reduced insect cuticle-degraded enzyme production due to the prolonged storage of the isolate at the artificial media, such as PDA. Decreasing insect cuticle-degraded enzyme production also can be caused by recultured the isolate at artificial media too many times without reinfection to the insect. Nutrition of artificial media to storage and recultured will affected the virulence of produced spore [14]. Fungal infection is also affected by temperature and water activity because each fungus has its optimal temperature and water activity to sporulation and growth. Metarhizium sp. optimal for increased temperature higher than $30{ }^{\circ} \mathrm{C}$ in the environment with water activity between $0.94-0.995$ [15].

$T$. viride, which cannot infect $S$. litura, is a soil fungus, not an entomopathogen but $T$. viride has the potential as biocontrol because of antagonism and parasitism against other fungi [16]. T. viride produces the chitinolytic and glucanolytic enzyme, but $T$. viride enzyme structure not available to the degraded exoskeleton of the insect. Chitinase of $T$. viride has a different protein structure to the chitinase of entomopathogenic [17].

Azadirachta indica extract that directly sprayed to $S$. litura body caused S. litura mortality because of the extract containing azadirachtin. Azadirachtin came into the $S$. litura body through the cuticle, spiracle, or other sensory organ and then paralyzed neuron of the insect body [18]. Azadirachtin neurotoxin was targeted the neuroendocrine system. The 
effect of azadirachtin caused the color of S. litura larva to become darker and then died [19]. Azadirachtin and other active compounds, such as meliantriol, salanin, and nimbin, can affect the feeding ability, growing of $S$. litura body, reproduction ability, molting process, disturbing hybridization and sexual communication, decreasing of egg hatching ability, and disturbing chitin forming [20].

Azadirachtin and other active compounds entering the digestion system through the sprayed leaves that fed to the S. litura. Azadirachtin and other active compound reach the breathing-trachea system, entering blood circulation and the neuro system. Azadirachtin disturbing electron transfer on the mitochondria, which will disturb the cardiovascular system, breathing system, and neuro system, and make the $S$. litura died. Disturbed neuro systems also will be affected by the hormone, such as exdison [21].

Adding wood vinegar to the formulation showed an increase to the $S$. litura mortality rate. Wood vinegar as an additional component has the potential to increase the activity of the active compound of $A$. indica extract because the acetic acid in wood vinegar can help penetrate the toxin into the larvae body more effective because acetic acid will interfere with cuticle permeability [22]. Further research is needed in various aspects including direct application of Agr2 to plants in the field to ensure the formula does not affect plant health and also to find an efficient dosage and method of application.

\section{References}

1. G.V.R. Rao, J.A. Wightman, D.V.R. Rao, Insect Sci. Appl. 14 (1993)

2. T. Trizelia, M. Syahrawati, A. Mardiah, JEI. 8, 1 (2011)

3. G. Nagal, K.S. Verma, L. Rathore, Adv. Life Sci. 5, 3 (2016)

4. Y. Prayogo, W. Tengkano, Marwoto, Jurnal Litbang Pertanian 24, 1 (2005)

5. S. Mantzoukas, P.A Eliopoulos, Applied Science 10, 1 (2020)

6. R.T Gahukar, Crop. Prot. 62 (2014)

7. A.H. Prianto, N.F.N. Budiawan, Y. Yulizar, P. Simanjuntak, Bul. Littro. 30, 1 (2019)

8. R. Bezzar-Bendjazia, S. Kilani-Morakchi, F. Maroua, N. Aribi, Pestic. Biochem. Physiol. 143 (2017)

9. Er, Aylin, D. Taşkıran, and O. Sak, Arch. Biol. Sci. 69, 2 (2017)

10. B. Shu, J. Zhang, G. Cui, R. Sun, X. Yi, G. Zhong, Front. Physiol. 9, 137 (2018)

11. G. Schmahl, K.A.S. Al-Rasheid, F. Abdel-Ghaffar, S. Klimpel, H. Mehlhorn, Parasitol. Res. 107 (2010)

12. V.K. Dua, A.C. Pandey, K. Raghavendra, A. Gupta, T. Sharma, A.P. Dash, Malar. J. 8,124 (2009)

13. M. Debashri, M. Tamal, Res. J. Recent Sci. 1, 3 (2021)

14. F.A. Shah, C.S. Wang, T.M. Butt, FEMS Microbiol. Lett. 251 (2005)

15. O.A. Borisade, N. Magan, Biocontrol Sci. Technol. 24, 9 (2014)

16. R.P. Collins, A.F. Halim, J. Agric. Food Chem, 20, 2 (1972)

17. G.E. Harman, Phytopathology 96, 2 (2006)

18. A.A.L.N. Dewi, I.W. Karta, N.L.C. Wati, N.M.A. Dewi, Jurnal Sains dan Teknologi 6, $1(2017)$

19. S.S. Martinez, H.F. van Emden. Neotrop. Entomol. 30, 1 (2001)

20. I.P.A.H. Wibawa, Jurnal Agroekoteknologi Tropika 8, 1 (2019)

21. I.M. Merdana, I.A.P. Hapsari, F. Muslih, Buletin Veteriner Udayana 12, 1 (2020)

22. D.H. Kim, H.E. Seo, S.C. Lee, K.Y. Lee, Animal Cells and Systems 12, 1 (2008) 